Conde-Sala JL, Garre-Olmo J, Turró-Garriga O, López-Pousa S, Vilalta-Franch J. Factors related to perceived quality of life in patients with Alzheimer's disease: the patient's perception compared with that of caregivers. International Journal of Geriatric Psychiatry 2009; 24: 585-594.

\title{
Factors related to perceived quality of life in patients with Alzheimer's
} disease: the patient's perception compared with that of caregivers

Josep Lluís Conde-Sala ${ }^{1}$, Josep Garre-Olmo ${ }^{2}$, Oriol Turró-Garriga ${ }^{2}$,

Secundino López-Pousa ${ }^{2}$ and Joan Vilalta-Franch ${ }^{2}$

${ }^{1}$ University of Barcelona, Developmental Psychology, Barcelona, Spain

${ }^{2}$ Institut Assistència Sanitaria, Research Unit, Salt, Girona, Spain

*Correspondence to: J. L. Conde-Sala, University of Barcelona,

Developmental Psychology, Barcelona, Spain.

E-mail: jllconde@ub.edu 


\begin{abstract}
Aims: To compare care recipient and caregiver perceptions of quality of life in patients (QoLp) with Alzheimer's disease (AD). To identify associated factors, and the concordancesdiscrepancies.
\end{abstract}

Method: Cross-sectional analytic study of 236 patients and their carers using the Quality of Life in Alzheimer's Disease (QoL-AD) scale, socio-demographic data and clinical examination.

Results: Patients scored the QoL-AD more favourably than did caregivers (34.4 vs. 31.3, $\mathrm{p}<0.001$ ). Cognitive deterioration did not affect the perception of QoL-AD ( $r h o=-0.05$, $\mathrm{p}=0.394)$. The neuropsychiatric symptoms was associated with a negative perception of the QOL-AD in both patients ( $r h o=-0.22, \mathrm{p}<0.01$ ) and caregivers (rho $=-0.47, \mathrm{p}<0.001$ ). Greater functional autonomy was associated with a better perception of the QOL-AD in patients ( $\mathrm{rho}=$ $0.17, \mathrm{p}<0.01)$ and even more so in caregivers ( $\mathrm{rho}=0.56, \mathrm{p}<0.001)$. In carers, burden (rho= $0.56, \mathrm{p}<0.001)$ and mental health $(\mathrm{rho}=0.31, \mathrm{p}<0.001)$ were inversely associated with the QoL-AD. QoL-AD scores of both patients and caregivers were higher for men, married subjects, those who lived with their spouse and those living in their own home. When the carer was a spouse both patients and caregivers scored the QoL-AD higher than when the carer was a son or daughter ( 35.5 vs. 33.4 and 33.7; 32.9 vs. 30.5 and 27.7, $\mathrm{p}<0,001)$.

Conclusions: Patients have a better perception of QoL-p. Caregivers give a more negative evaluation of neuropsychiatric symptoms, but have a more positive view of functional autonomy. Carers who are spouses have a better perception of QoL-p than do carers who are sons or daughters.

Keywords: Quality of Life, Alzheimer's disease, Caregivers. 


\section{Introduction}

Alzheimer's disease (AD) is a significant public health concern due to its high prevalence, the serious consequences for patients, and the burden it places on families (Garre-Olmo et al., 2000). Given the enormous costs to the individual and the family that derive from the chronicity and severity of the disease one of the key objectives of the services offered to patients and their relatives is therefore to maintain quality of life.

The concept of and emphasis placed on the quality of life of patients (QoL-p) with dementia has emerged particularly over the last decade (Whitehouse et al., 2003; Lucas-Carrasco, 2007), and evaluation of this aspect has been progressively included as part of clinical guidelines for treating dementia patients. Since 2001 the Group for Harmonization of Dementia Drug Guidelines and the Alzheimer's Society (Mack and Whitehouse, 2001) have recommended the evaluation of quality of life to verify the efficacy and appropriateness of therapeutic interventions, not only from the patient's perspective but also from that of family caregivers or professionals. However, research is still needed to clarify a number of key questions: which measures are the most valid and reliable for assessing QoL-p, what is the best type of administration (auto or rater-administrated questionnaire) according to the degree of cognitive impairment, who are the best informants, and which factors influence the perception of QoL-p in patients and other informants (Naglie, 2007).

The aims of the present study were, firstly, to compare the perceptions of patients and family caregivers of QoL-p in AD; secondly, to identify the socio-demographic and clinical factors associated with the care recipient and caregiver perception of QoL-p; and thirdly, to identify the points of agreement and disagreement between patients and carers as regards QoL-p.

\section{Method}

\section{Study population}

The sample comprised 236 patients diagnosed with AD according to DSM-IV (APA, 2001) criteria and probable AD according to NINCDS-ADRDA (McKhann et al., 1984) criteria, along with their corresponding family caregivers. The main carer was defined as the person who was responsible for helping the patient with daily living activities, both basic (self-care 
such as bathing, dressing and undressing, etc.) and instrumental (personal autonomy such as using the telephone or managing money), as well as for supervising him or her at home.

All the AD subjects were seen as out-patients in the Memory and Dementia Assessment Unit of the Santa Caterina Hospital in Girona (Spain) and formed part of the SIDEA research project (Seguimiento Integral de la Enfermedad de Alzheimer - Comprehensive Follow-Up of Alzheimer's Disease). This is a four year observational, longitudinal and pragmatic cohort study. Using a standardized protocol it aims to describe and follow-up a large cohort of patients diagnosed with Alzheimer's disease, as well as their family caregivers, who receive outpatient medical and social care at secondary-level centres in our area. The study was approved by the Ethics Committee for Clinical Research of the local health authority. All the patients and their carers gave their written consent to participate in the study. The data analysed corresponded to the baseline assessment session of the SIDEA study.

\section{Procedure}

In the initial interview the aims of the study were explained to patients and caregivers, who were then interviewed separately. The assessment instruments were administered by a clinical neuropsychology research team from the hospital.

\section{Study protocol}

\section{Measuring quality of life}

The Quality of Life in Alzheimer's Disease (QoL-AD) scale was administered to patients and caregivers in order to assess their perception of QoL-p. The scale consists of thirteen items that reflect the subject's perception of different aspects related to wellbeing: physical health, energy, mood, living situation, memory, family, marriage, friends, self as a whole, ability to do chores around the house, ability to do things for fun, money, and life as a whole. Possible scores range from 13 to 52 (Logsdon et al., 1999; 2002).

\section{$\underline{\text { Instruments for examining socio-demographic and clinical variables }}$}

The socio-demographic characteristics of the patient and caregiver (age, gender, marital status, level of education, place of residence, family relationship, whether they lived together, employment situation, other family burdens such as children or disabled people care) were 
recorded by means of a structured interview, the Cambridge Mental Disorders of the Elderly Examination (CAMDEX-R, Sections A and H ) (Roth et al., 1986).

The clinical examination of the patient was conducted using the following instruments:

- Cambridge Cognitive Examination-Revised (CAMCOG-R). This forms part of the CAMDEX and assesses various cognitive functions, with possible scores ranging from 0 to 107, with the cut-off point for the Spanish population being 68/69 (Vilalta-Franch et al., 1990).

- Mini Mental State Examination (MMSE). A brief cognitive examination whose scores range from 0 to 30, the cut-off point for cognitive impairment being 21/22 (Folstein et al., 1975). This was used to evaluate the severity of cognitive impairment (Kraemer et al., 1998).

- Disability Assessment for Dementia (DAD). This scale assesses a wide range of daily living activities (ADL): basic, instrumental and leisure. It comprises 40 items and scores range from 0-100. (Gélinas et al., 1999; Feldman et al., 2001).

- Neuropsychiatric Inventory (NPI). This instrument for evaluating psychiatric symptomatology in $\mathrm{AD}$ is administered to the carer. It comprises twelve subscales and score ranges from 0 to 144. (Cummings et al., 1994; Vilalta-Franch et al., 1999).

The clinical examination of the carer was conducted using the following instruments:

- SF-12 Health Survey (SF-12v1) Short form of the SF-36 Health Survey. It comprises twelve items and scores range from 12 to 47 . Two global dimensions can be obtained from the direct scores: physical health and mental health, and in both dimensions the score ranges from 0 to 100 (Ware et al., 1996; Alonso et al., 1998).

- Caregiver Burden Interview (CBI). A questionnaire designed to assess the burden experienced by carers. It comprises 22 items and scores range from 0 to 88 (Zarit et al., 1986; Martín et al., 1996).

\section{Statistical analysis}

A descriptive analysis of the data was conducted and differences in means for the QoL-AD scale were calculated using the non-parametric Wilcoxon signed-rank test. The degree of correlation and concordance between the scores of patients and caregivers on the QoL-AD were also analysed by means of Spearman's rank correlation coefficient and the Kappa index, respectively.

The analysis of relationships between the scores of patients and caregivers on the QoL-AD and the socio-demographic and clinical factors of patients and caregivers was conducted using 
the non-parametric Mann-Whitney U and Kruskal-Wallis tests. The correlations used were Pearson's for continuous variables and Spearman's for discontinuous variables.

When the comparison of two means revealed significant differences Cohen's $d$ was used as a measure of effect size.

In order to determine the overall effect of the clinical and socio-demographic variables on the perception of QoL-p in patients and caregivers, two multivariate linear regression analyses were carried out. The dependent variables were scores on the QoL-AD of the patient and caregiver, while the independent variables were those found to be significant in the bivariate analysis.

Statistical significance was set at 0.05 in order to compare hypotheses.

\section{Results}

\section{Description of the sample}

The mean age of patients was 77.8 (s.d. =6.9) and that of caregivers 59.9 (s.d. = 14.6). Of the patient group 79 were men (33.5\%) and 157 women (66.5\%), while caregivers were 70 men (29.7\%) and 166 women (70.3\%). As regards the family relationship, 103 (43.6\%) caregivers were the patient's spouse and $109(46.2 \%)$ were the son or daughter. The number of caregivers who lived with the patient was 153 (64.8\%), while $83(35.2 \%)$ supervised the care of but did not live with the patient (Table 1).

\section{Clinical data}

The mean score of patients on the CAMCOG was 56.0 (s.d. = 11.6). Seventy-six patients (32.2\%) patients had mild cognitive impairment (MMSE > 20), 154 (65.3\%) showed moderate cognitive impairment $(\mathrm{MMSE}=11-20)$, and $6(2.5 \%)$ had severe cognitive impairment (MMSE <11). The mean DAD score was $85.4($ s.d. $=8.0)$ and the mean total score on the NPI was 10.6 (s.d. $=12.2)$.

The clinical questionnaires administered to caregivers revealed a mean score on the SF-12 of 46.7 (s.d. $=10.9$ ) and 49.4 (s.d. = 9.3) for the mental and physical health dimensions, respectively. The mean score on the CBI was 40.7 (s.d. =12.3) (Table 2). 


\section{Perception of QoL-p in patients and caregivers}

The item "marriage" from the QoL-AD scale was only applied to patients and caregivers when the patients had a spouse $(n=148)$ at the time of the interview; for each of the remaining subjects $(n=88)$ the scores for this item were weighted according to the total scale score.

The total mean score of the QoL-AD scale showed that patients $($ mean $=34.4$; s.d. $=4.6)$ and caregivers $($ mean $=31.3$; s.d. $=5.2$ ) had a different subjective perception of QoL-p, this difference being significant $(z=-7.462 ; p<0.001 ; d=0.628)$ with a medium/high effect size. Patients also scored significantly higher on all items except living situation. Particularly noteworthy among these differences was that for memory $(z=-6.479 ; p<0.001 ; d=0.642)$ (Table 3).

\section{Patient factors associated with the perception of QoL-p in patients and caregivers}

The analysis of associations between the socio-demographic data of patients and QoL-AD scores (Table 4) revealed, for patients, higher perceived QoL-p for men $(p<0.001 ; d=0.612)$, those who were married, who lived with their spouse and those who lived in their own home. The data for caregivers showed agreement on all these aspects: men, those who were married, who lived with their spouse $(\mathrm{p}<0.001 ; \mathrm{d}=0.812)$ and those who lived in their own home; an additional factor here was younger age.

There were no significant differences in the QoL-AD score according the educational groups, neither among patients nor caregivers.

The most relevant clinical factor was depression, as lower scores for QoL-p were given by patients who scored high on NPI-depression $(p<0.001)$. Smaller but still significant correlations were also observed for NPI-apathy, NPI-total score and greater autonomy on the $\operatorname{DAD}(\mathrm{p}<0.01)$.

In caregivers the significant correlations with clinical data were more diverse. The DAD, NPI-apathy, NPI-total, NPI-depression and NPI-appetite all showed greater significant correlations $(\mathrm{p}<0.001)$, as did, with a smaller effect, NPI-agitation, NPI-anxiety and NPIelation $(p<0.01)$.

No significant correlations were observed, for either patients or caregivers, between QoL-AD scores and cognitive tests.

As regards gender, patients and caregivers agreed in perceiving that men had better QoL-p. Examination of the clinical data of patients showed that the only significant differences 
related to gender concerned depression and anxiety, with higher scores for women: NPIdepression $(z=-2.572 ; p<0.01)$ and NPI-anxiety $(z=-3.696 ; p<0.001 ; d=-0.512)$.

\section{Caregiver factors associated with the perception of QoL-p in patients and caregivers}

Comparison of the socio-demographic data for caregivers with QoL-AD scores (Table 5) revealed that both patients $(\mathrm{p}<0.001)$ and caregivers $(\mathrm{p}<0.01)$ perceived better QoL-p when the caregiver was older.

Patients and caregivers agreed in scoring higher QoL-p when the caregiver was a spouse without other family burdens, who was the sole carer and who lived with the patient.

No significant differences were found as regards gender, years of education, marital status or the employment situation of caregivers.

In terms of clinical factors, caregivers with a higher correlation on the mental health dimension ( $r$ ho $=0.311 ; \mathrm{p}<0.001$ ) perceived better QoL-p, while those with high levels of burden perceived worse QoL-p (rho $=0.562 ; \mathrm{p}<0.001)$.

\section{Spouse caregivers and son/daughter caregivers in relation to QoL-p}

Son/daughter caregiver scores $($ mean $=30.5$; s.d. $=5.3$ ) on the QoL-AD were significantly lower than those of spouse caregivers (mean $=32.9 ;$ s.d. $=4.4) ;(\mathrm{z}=-3.272 ; \mathrm{p}<0.01 ; \mathrm{d}=$ 0.477). A similarly significant difference was also observed in the QoL-AD of patients with son/daughter caregivers $($ mean $=33.4$; s.d. $=4.6)$ compared to those who were cared for by a spouse $($ mean $=35.5$, s.d. $=4.2) ;(z=-3.366 ; \mathrm{p}<0.01 ; \mathrm{d}=0.418)$.

The level of burden of son/daughter caregivers $(\mathrm{CBI}=42.4$; s.d. $=12.7)$ was greater than that of spouse caregivers $(\mathrm{CBI}=37.7$; s.d. $=10.2)$, this difference being significant $(\mathrm{z}=-2.723$; $\mathrm{p}<0.01 ; \mathrm{d}=0.414)$. The correlation between caregiver burden and the QoL-AD was significant for the two groups $(\mathrm{p}<0.001)$, although the value was higher in the case of sons/daughters (son/daughter caregivers, rho $=-0.636$; spouse caregivers, rho $=-0.508$ ).

As regards physical health, spouse caregivers (SF-12 = 45.9; s.d. $=9.7)$ suffered the effects more than did son/daughter caregivers $(\mathrm{SF}-12=52.5$; s.d. $=8.1)$, this difference being highly significant $(\mathrm{z}=-5.177 ; \mathrm{p}<0.001 ; \mathrm{d}=0.715)$; however, there was no significant correlation with the QoL-AD score of patients and caregivers.

With respect to the mental health dimension, spouse caregivers had better health (SF-12 = 48.4 ; s.d. $=9.1)$ than son/daughter caregivers $(\mathrm{SF}-12=44.3$; s.d. $=12.6)$, this difference being less significant $(\mathrm{z}=-2.005 ; \mathrm{p}<0.05)$; however, the correlation between mental health and the 
QoL-AD was only significant and in a positive direction (the better the mental health, the higher the QoL-p score) for son/daughter caregivers ( rho $=0.428 ; \mathrm{p}<0.001$ ).

\section{Multivariate linear regression analysis}

The linear regression analysis (Table 6) revealed that the QoL-AD patient score predictors were, in patients, depression $(p<0.001)$, gender $(p<0.01)$ and the DAD score $(p<0.05)$; in caregivers the predictors were the DAD score $(\mathrm{p}<0.001)$, apathy $(\mathrm{p}<0.001)$ and depression $(\mathrm{p}<0.01)$. The coefficient of determination of the multivariate model was 0,298 . The QoL-AD caregiver score predictors were, in patients, age and caregiver burden $(p<0.05)$; in caregivers the predictors were burden $(p<0.001)$, mental health and family relationship $(p<0.05)$. The coefficient of determination of the multivariate model was 0,522 .

\section{Discussion}

\section{Differences in the perception of QoL-p}

Concordance between the two QoL-AD scores, measured by means of the Kappa index, was low for all items, as only correlations above 0.4 can be considered clinically significant. This differing perception of patients and caregivers, with better scores among patients, is similar to that reported by other studies (Thorgrimsen et al., 2003; Sands et al., 2004; Ready et al., 2006). In addition, and in line with previous research (Hoe et al., 2005; Vogel et al., 2006), the perception of QoL-p was not correlated in either patients or caregivers with levels of cognitive impairment; indeed, the better scores among patients were preserved, with a similar difference between patients and caregivers for all levels of impairment. Studies that compared the perception of patients with that of the professionals caring for them also report better QoL-p scores among patients (Cheon et al., 2005; Hoe et al., 2006).

In global terms there appear to be two independent and distinct points of view (Ready et al. 2006), in which the disease situation seems to affect caregivers more than patients themselves. In this regard, it should be noted that studies of subjective wellbeing in dementia (Livingston et al., 2008) and in normal ageing (Mroczek and Kolarz, 1998) also report this paradox, namely the presence of high levels of well-being in the face of objective difficulties or contextual or socio-demographic risk factors that intuitively would be expected to cause unhappiness. 


\section{Clinical factors}

Neuropsychiatric symptoms in the patient (depression and apathy) were associated with lower perceived QoL-p in both the patient and caregiver groups. Among the neuropsychiatric symptoms associated with lower QoL-p, relatives included those that imply heightened motor activity (agitation, anxiety, elation and aberrant motor behaviour) and which placed an increased burden on the caregiver.

The correlation between the degree of autonomy for ADL and the QoL-AD was significant for both patients and caregivers, although it was of greater relevance for the latter. From the caregivers' perspective, reduced autonomy implied a greater global impairment in the patient, and therefore greater burden for the caregiver.

Among caregivers the degree of burden and mental health were inversely associated with perceived QoL-p: a greater burden was linked to lower perceived QoL-p while a higher score on the mental health dimension was associated with a higher score for perceived QoL-p.

The linear regression analysis revealed that the most important predictors were depression, for patients, and autonomy in ADL, apathy and caregiver burden for carers. In line with several previous studies depression in the patient was the main clinical factor associated with lower perceived QoL-p in patients themselves (Sands et al., 2004; Cheon et al., 2005; Selwood et al., 2005; Vogel et al., 2006; Hoe et al., 2006; Fuh and Wang, 2006; Hoe et al., 2007). In caregivers the main clinical factors associated with lower perceived QoL-p were caregiver burden (Thorgrimsen et al., 2003; Sands et al., 2004), autonomy for ADL (Cheon et al., 2005; Hoe et al., 2006; Hoe et al., 2007) and apathy (Hoe et al., 2007). In fact, these three aspects could be considered to be related: depressive symptoms increase functional disability (ADL), are associated with an increased presence of non-cognitive symptoms and, overall, increase caregiver burden (Garre-Olmo et al., 2002).

Despite the differences indicated between patients and caregivers, however, it should be noted that some studies which compared the perceptions of patients and professionals reported even greater discrepancies, both qualitatively and quantitatively, among the factors associated with QoL-p. Whereas the predominant factors among patients were depression and anxiety, professionals cited the increasing problems of dependency and behaviour (Hoe et al., 2006). 


\section{Socio-demographic factors}

The analysis of the socio-demographic factors that affect patient and caregiver perceptions of QoL-p according to the QoL-AD scale proved to be a more complex and novel task. Two aspects need to be highlighted here.

Gender of the patient: Patients and caregivers agreed in perceiving better QoL-p in patients who were men. The results indicate that women had higher levels of depression and anxiety, as occurs in the general population (Regier et al., 1993; Copeland et al., 1999). This finding is consistent with what is observed in clinical practice when offering support to relatives of patients with Alzheimer's disease, and could also be related to the greater difficulties women face in terms of continuing to perform the tasks associated with their role in the family and generational context (Conde-Sala, 2006).

Relationship of the caregiver to the patient: The data show that caregivers had a more positive perception of QoL-p when patients were married, lived with their spouse or lived in their own home. At the same time, older caregivers, those who were the patient's spouse, who lived with him/her, were the sole carer and who had no other family burdens scored higher for QoL -p. These results suggest that two clearly distinct subgroups could be defined within the group of family caregivers: spouse caregivers and son/daughter caregivers. In this regard, son/daughter caregivers scored lower for perceived QoL-p than did spouse caregivers. This difference was also observed among patients: those who were cared for by a son or daughter scored lower for perceived QoL-p than did those who were looked after by a spouse.

Given the results obtained it would not seem that this difference can be explained by any especially relevant or differential clinical factor linked to patients. Furthermore, the only clinical factor for caregivers of relevance here would be burden, which was high in both subgroups, although more so in the group of son/daughter caregivers.

One explanation for these differences could be the nature of the family relationship between patient and caregiver and the factors associated with this. Spouse caregivers would be closer to the patient in many aspects of life such as age, the fact of living together, and family and generational factors, and in this context the task of caring for the patient would occupy a sizeable proportion of their life together, thus generating greater empathy between them. In contrast, for son/daughter caregivers the abovementioned aspects of life would not only be more distant but may clash with other obligations: work, their own children, etc.

The analysis of socio-demographic data thus suggests that when it comes to perceived QoL-p, caregivers should not be treated as a uniform group; rather, the family relationship variable 
(spouse vs. son/daughter) should be introduced in order to observe the behaviour of the two sub-groups with respect to clinical and socio-demographic data.

\section{Clinical implications}

The results of the present study, especially those obtained in the multivariate linear regression analysis, support the importance of treating depression in patients with Alzheimer's disease; depression is not only associated with other neuropsychiatric (NPI) and functional (ADL) symptoms (Garre-Olmo et al., 2003), but also has repercussions for the quality of life of both patients and their relatives (López-Pousa et al., 2007).

As regards caregivers it is important to address aspects related to burden and mental health. Information about the disease, the provision of healthcare resources, and social and emotional support are clearly necessary to reduce caregiver burden, which not only affects carers but also, in an indirect way, patients (Conde-Sala, 2006). Thus, the mental health needs of caregivers must be taken into account and evaluated, as this aspect affects the perception of QoL-p, especially when the carer is a son or daughter.

The distinction between spouse and son/daughter caregivers has implications for the approach of professionals in alleviating the symptoms of caregiver burden; indeed, the different position in the relationship and social/family situation generates different behaviours and perceptions as regards QoL-p depending on whether the caregiver is the spouse or son/daughter of the patient.

\section{Limitations}

As already indicated, analysing caregivers as a uniform group may undermine some of the results, and it would be advisable to distinguish between spouse and son/daughter caregivers and the relationship between these two sub-groups and perceived QoL-p for all the data; further studies are thus required in order to consider these differences in greater detail.

The data from participants correspond to the baseline interview of the study. It would therefore be useful to observe the evolution in perceived QoL-p in both patients and caregivers in a subsequent longitudinal study. 


\section{References}

Alonso J, Regidor E, Barrio G, et al.1998. Valores poblacionales de referencia de la versión española del Cuestionario de Salud SF-36. Med Clin (Barc) 111: 410-416.

American Psychiatric Association.2001. Manual diagnóstico y estadístico de los trastornos mentales. 4 ed., texto revisado (DSM-IV-TR). Masson: Barcelona.

Cheon JS, Cho W, Oh BH. 2005. Predictors of Quality of Life in Patients with Dementia of the Alzheimer's Type. Korean Geriatr Psychiatry 9: 63-69.

Conde-Sala JL.2006. Demencia y familiares cuidadores. Deterioro, sobrecarga y apoyo social. In Enfermedad de Alzheimer y otras demencias $3^{\circ}$ ed., Alberca R, López-Pousa S. (ed). Editorial Panamericana: Madrid; 109-121.

Copeland JR, Beekman AT, Dewey ME, et al. 1999. Depression in Europe. Geographical distribution among older people. Br J Psychiatry 174: 312-321.

Cummings JL, Mega M, Gray K, et al. 1994. The neuropsychiatric inventory. Comprehensive assessment of psychopathology in dementia. Neurology 44: 2308-2314.

Feldman H, Sauter A, Donald A, et al. 2001. The disability assessment for dementia scale: a 12-month study of functional ability in mild to moderate Alzheimer disease. Alzheimer Dis Assoc Disord 15: 8995.

Folstein MF, Folstein SE, McHugh PR. "Mini Mental State". 1975. A practical method for grading the cognitive state of patients for the clinician. J Psychiatr Res 12: 189-198.

Fuh JL, Wang SJ. 2006. Assessing quality of life in Taiwanese patients with Alzheimer's disease. Int J Geriatr Psychiatry 21:103-107.

Garre-Olmo J, Hernández-Ferrándiz M, Lozano-Gallego M, et al. 2000. Burden and quality of life in carers of patients with Alzheimer type dementia. Rev Neurol 31:522-527.

Garre-Olmo J, López-Pousa S, Vilalta-Franch J, et al. 2002. Carer's burden and depressive symptoms in patients with Alzheimer s disease. State after twelve months. Rev Neurol 34: 601-607.

Garre-Olmo J, López-Pousa S, Vilalta-Franch J, et al. 2003. Evolution of depressive symptoms in Alzheimer disease: one-year follow-up. Alzheimer Dis Assoc Disord 17:77-85.

Gélinas I, Gauthier L, McIntyre M, et al.1999. Development of a functional measure for persons with Alzheimer's disease: the Disability Assessment for Dementia. Am J Occup Ther 53: 471-481.

Hoe J, Hancock G, Livingston G, et al. 2006. Quality of life of people with dementia in residential care homes. Br J Psychiatry 188: 460-464.

Hoe J, Katona C, Roch B, et al. 2005. Use of the QOL-AD for measuring quality of life in people with severe dementia--the LASER-AD study. Age Ageing 34:130-135.

Hoe J, Katona C, Orrell M, et al. 2007. Quality of life in dementia: care recipient and caregiver perceptions of quality of life in dementia: the LASER-AD study. Int J Geriatr Psychiatry 22:1031-1036. 
Kraemer HC, Taylor JL, Tinklenberg JR, Yesavage JA 1998. The stages of Alzheimer's disease: a reappraisal. Dement Geriatr Cogn Disord 9: 299-308.

Livingston G, Cooper C, Woods J, et al. 2008.. Successful ageing in adversity: the LASER AD longitudinal study. J Neurol Neurosurg Psychiatry 79: 641-645.

Logsdon RG, Gibbons LE, McCurry SM, et al. 1999. Quality of life in Alzheimer's disease: patient and caregiver reports. J Mental Health Aging 5: 21-32.

Logsdon RG, Gibbons LE, McCurry SM, et al. 2002. Assessing quality of life in older adults with cognitive impairment. Psychosom Med 64: 510-519.

López-Pousa S, Vilalta-Franch J, Garre-Olmo J, et al. 2007. Caracterización y prevalencia de los síntomas psicológicos y conductuales en pacientes con demencia. Rev Neurol 45: 683-688.

Lucas-Carrasco R.2007. Quality of life and dementia. Med Clin (Barc) 128: 70-75.

Mack JL, Whitehouse PJ. 2001. Quality of life in dementia: state of the art- report of the International Working Group for Harmonization of Dementia Drug Guidelines and the Alzheimer's Society satellite meeting. Alzheimer Dis Assoc Disord 15: 69-71.

Martín M, Salvadó I, Nadal S, et al. 1996. Adaptación para nuestro medio de la Escala de Sobrecarga del Cuidador (Caregiver Burden Interview) de Zarit. Rev Gerontol 6: 338-346.

McKhann G, Drachman D, Folstein M, et al. 1984. Clinical diagnosis of Alzheimer's disease: report of the NINCDS-ADRDA Work Group under the auspices of Department of Health and Human Services task force on Alzheimer's disease. Neurology 34: 939-944.

Mroczek DK, Kolarz CM. 1998. The effect of age on positive and negative affect: A developmental perspective on happiness. J Pers Soc Psychol 75:1333-1349.

Naglie G. 2007. Quality of life in dementia. Can J Neurol Sci 34 (suppl): s57-61.

Ready RE, Ott BR, Grace J. 2006. Insight and cognitive impairment: effects on quality-of-life reports from mild cognitive impairment and Alzheimer's disease patients. Am J Alzheimer's Dis Other Demen 21: 242-248.

Regier DA, Farmer ME, Rae DS, et al. 1993. One-month prevalence of mental disorders in the United States and sociodemographic characteristics: the Epidemiologic Catchment Area study. Acta Psychiatr Scand 88: 35-47.

Roth M, Tym E, Mountjoy CQ, et al. 1986. CAMDEX. A standardised instrument for the diagnosis of mental disorder in the elderly with special reference to the early detection of dementia. Br J Psychiatry 149: 698-709.

Sands LP, Ferreira P, Stewart AL, et al. 2004. What explains differences between dementia patients' and their caregivers' ratings of patients' quality of life? Am J Geriatr Psychiatry 12: 272-280.

Selwood A, Thorgrimsen L, Orrell M. 2005. Quality of life in dementia--a one-year follow-up study. Int J Geriatr Psychiatry 20:232-237. 
Snow AL, Dani R, Souchek J, et al. 2005. Comorbid Psychosocial Symptoms and Quality of Life in Patients With Dementia. Am J Geriatr Psychiatry 13: 393-401.

Thorgrimsen L, Selwood A, Spector A, et al. 2003. Whose quality of life is it anyway? The validity and reliability of the Quality of Life-Alzheimer's Disease (QoL-AD) scale. Alzheimer Dis Assoc Disord 17:201-208.

Vilalta-Franch J, Llinàs-Reglà J, López-Pousa S, et al. 1990. CAMDEX, validación de la adaptación española. Neurologia 5: 117-120.

Vilalta-Franch J, Lozano-Gallego M, Hernández-Ferrández M, et al. 1999. El inventario neuropsiquiátrico: propiedades psicométricas de su adaptación al castellano. Rev Neurol 29: 15-19.

Vogel A, Mortensen EL, Hasselbalch SG, et al. 2006. Patient versus informant reported quality of life in the earliest phases of Alzheimer's disease. Int J Geriatr Psychiatry 21: 1132-1138.

Ware JE Jr, Kosinski M, Keller SD. 1996. A 12-Item Short-Form Health Survey: construction of scales and preliminary tests of reliability and validity. Med Care 34: 220-233.

Whitehouse PJ, Patterson MB, Sami SA. 2003. Quality of life in dementia: ten years later. Alzheimer Dis Assoc Disord 17: 199-200.

Zarit SH, Todd PA, Zarit JM. 1986. Subjective burden of husbands and wives as caregiver: a longitudinal study. Gerontologist 26: 260-266. 
Table 1. Socio-demographic factors of participants

\begin{tabular}{|c|c|c|c|c|}
\hline Patients $(n=236)$ & & Caregivers $(n=236)$ & & \\
\hline Age, years & & Age, years & \multirow{2}{*}{\multicolumn{2}{|c|}{$59.9(14.6)$}} \\
\hline Mean (s.d.) & $77.8(6.9)$ & Mean (s.d.) & & \\
\hline Range & $55-93$ & Range & \multicolumn{2}{|c|}{$27-87$} \\
\hline Gender & & Gender & \multirow[b]{2}{*}{166} & \multirow[b]{2}{*}{$(70.3)$} \\
\hline Female, $n(\%)$ & $157(66.5)$ & Female, $n(\%)$ & & \\
\hline Marital status, $n(\%)$ & & Marital status, $n(\%)$ & & \\
\hline Married & $148(62.7)$ & Married & \multicolumn{2}{|c|}{$204 \quad(86.5)$} \\
\hline Widowed & $80 \quad(33.9)$ & Widowed & \multicolumn{2}{|c|}{$8 \quad(3.4)$} \\
\hline Single & $8 \quad(3.4)$ & Single & \multicolumn{2}{|c|}{$15 \quad(6.4)$} \\
\hline Divorced & -- --- & Divorced & \multicolumn{2}{|c|}{$9 \quad(3.8)$} \\
\hline Level of education, $n(\%)$ & & Level of education, $n(\%)$ & \\
\hline Illiterate, no schooling & $53(22.5)$ & Illiterate, no schooling & \multicolumn{2}{|c|}{$30 \quad(12.7)$} \\
\hline$<8$ years & $159(67.4)$ & $<8$ years & \multicolumn{2}{|c|}{$83 \quad(35.2)$} \\
\hline$>8$ years & $24(10.2)$ & $>8$ years & \multicolumn{2}{|c|}{$120 \quad(50.8)$} \\
\hline \multicolumn{2}{|l|}{ Living situation, $n(\%)$} & \multicolumn{3}{|c|}{ Family relationship of caregiver, $n(\%)$} \\
\hline With spouse & $120(50.8)$ & Spouse & 103 & $(43.6)$ \\
\hline With relative & $39(16.5)$ & Son/daughter & 109 & $(46.2)$ \\
\hline Alone & $34(14.4)$ & Other relative & 23 & $(9.7)$ \\
\hline Residence, $n(\%)$ & & Living with patient, $n(\%)$ & & \\
\hline Own home & $193(81.8)$ & Yes & 153 & $(64.8)$ \\
\hline \multirow[t]{9}{*}{ Relative's home } & $42(17.8)$ & Sole carer, $n(\%)$ & \multirow{3}{*}{\multicolumn{2}{|c|}{$137 \quad(58.1)$}} \\
\hline & & Yes & & \\
\hline & & Other family burdens, $n(\%)$ & & \\
\hline & & Yes & \multicolumn{2}{|c|}{$87 \quad(36.9)$} \\
\hline & & Employment situation, $n(\%)$ & & \\
\hline & & In work & 101 & $(43.3)$ \\
\hline & & Retired & 98 & $(42.1)$ \\
\hline & & Housewife & 26 & $(11.2)$ \\
\hline & & Unemployed & 8 & $(3.4)$ \\
\hline
\end{tabular}


Table 2. Clinical factors of participants

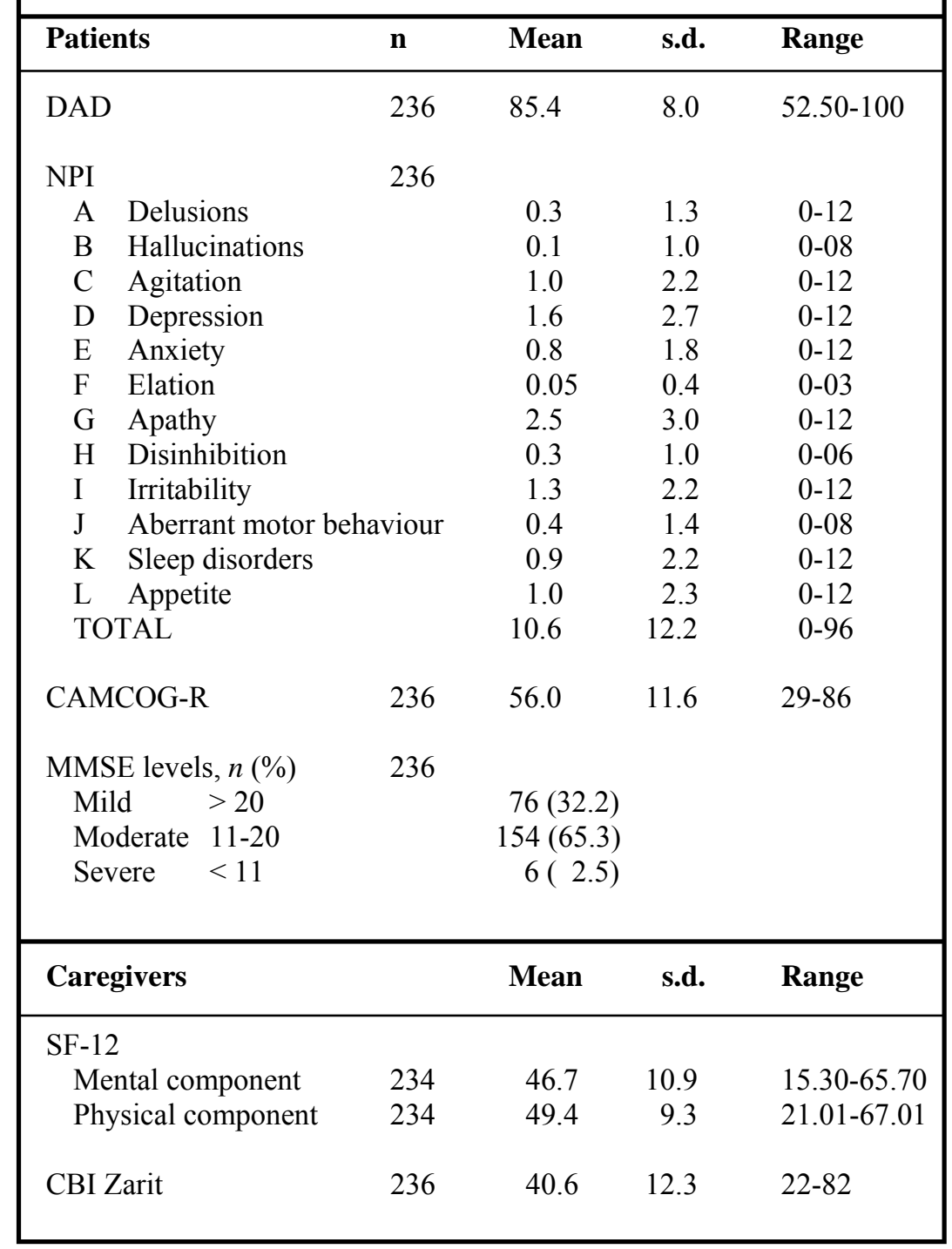

DAD: Disability Assessment for Dementia; NPI: Neuropsychiatric Inventory; CAMCOG-R: Cambridge Cognitive Examination-Revised; MMSE: Mini Mental State Examination SF-12: Short Form of Health Survey; CBI: Caregiver Burden Interview 
Table 3. Patient's quality of life according to the QoL-AD score of patients and caregivers

\begin{tabular}{|c|c|c|c|c|c|c|c|c|c|c|}
\hline \multirow[t]{2}{*}{ QoL-AD } & \multicolumn{2}{|c|}{ Patients } & \multicolumn{2}{|c|}{ Caregivers } & \multicolumn{2}{|c|}{ Wilcoxon } & \multirow[t]{2}{*}{ Cohen's $d$} & \multicolumn{2}{|c|}{ Spearman coeff. } & \multirow{2}{*}{$\begin{array}{c}\text { Kappa } \\
\mathbf{k}\end{array}$} \\
\hline & Mean & s.d. & Mean & s.d. & $\mathbf{z}$ & $p$ & & rho & $p$ & \\
\hline Physical health & 2.6 & 0.6 & 2.5 & 0.7 & -2.127 & 0.033 & 0.169 & 0.297 & 0.000 & 0.229 \\
\hline Energy & 2.5 & 0.7 & 2.3 & 0.7 & -3.646 & 0.000 & 0.300 & 0.287 & 0.000 & 0.191 \\
\hline Mood & 2.4 & 0.7 & 2.1 & 0.7 & -5.925 & 0.000 & 0.420 & 0.316 & 0.000 & 0.175 \\
\hline Living situation & 2.8 & 0.5 & 2.7 & 0.6 & -0.229 & 0.819 & 0.018 & 0.093 & 0.153 & 0.066 \\
\hline Memory & 2.0 & 0.6 & 1.6 & 0.5 & -6.479 & 0.000 & 0.642 & 0.055 & 0.401 & 0.080 \\
\hline Family & 3.2 & 0.5 & 3.0 & 0.6 & -5.109 & 0.000 & 0.467 & 0.134 & 0.040 & 0.059 \\
\hline Marriage & 3.2 & 0.6 & 2.9 & 0.6 & -4.740 & 0.000 & 0.496 & 0.225 & 0.006 & 0.171 \\
\hline Friends & 3.0 & 0.6 & 2.6 & 0.8 & -5.348 & 0.000 & 0.447 & 0.265 & 0.000 & 0.169 \\
\hline Self as a whole & 2.7 & 0.5 & 2.5 & 0.6 & -5.685 & 0.000 & 0.491 & 0.264 & 0.000 & 0.223 \\
\hline Ability to do chores & 2.6 & 0.6 & 2.2 & 0.7 & -5.385 & 0.000 & 0.451 & 0.301 & 0.000 & 0.214 \\
\hline Ability to do things for fun & 2.3 & 0.7 & 2.0 & 0.8 & -4.737 & 0.000 & 0.398 & 0.293 & 0.000 & 0.180 \\
\hline Money & 2.8 & 0.5 & 2.6 & 0.6 & -2.990 & 0.003 & 0.247 & 0.142 & 0.030 & 0.100 \\
\hline Life as a whole & 2.7 & 0.5 & 2.6 & 0.6 & -3.510 & 0.000 & 0.298 & 0.255 & 0.000 & 0.194 \\
\hline Total score & 34.4 & 4.6 & 31.3 & 5.2 & -7.462 & 0.000 & 0.628 & 0.360 & 0.000 & .......... \\
\hline
\end{tabular}

QoL-AD: Quality of Life in Alzheimer's Disease 
Table 4. Patient factors and relationships with the QoL-AD scale for patients and caregivers

\begin{tabular}{|c|c|c|c|c|c|c|c|c|c|}
\hline \multirow{2}{*}{ Patient factors } & \multirow[b]{2}{*}{$\mathbf{n}$} & \multirow[b]{2}{*}{ Mean } & \multicolumn{3}{|c|}{ QoL-AD patients } & \multicolumn{4}{|c|}{ QoL-AD caregivers } \\
\hline & & & s.d. & p Col & Cohen's $d$ & Mean & \multirow{2}{*}{$\begin{array}{c}\text { s.d. } \\
6.9\end{array}$} & $\mathbf{p}$ & \multirow[t]{2}{*}{ Cohen's $d$} \\
\hline Age $^{1}$ & 236 & 77.8 & 6.9 & $\begin{array}{l}\mathrm{r}=0.125 \\
p=0.054\end{array}$ & & 77.8 & & $\begin{array}{l}\mathrm{r}=-0.176 \\
p=0.007 * *\end{array}$ & \\
\hline \multicolumn{10}{|l|}{ Gender $^{2}$} \\
\hline Male & 79 & 36.1 & 3.7 & $z=-4.042$ & & 32.6 & 5.1 & $\mathrm{z}=-2.912$ & \\
\hline Female & 157 & 33.5 & 4.7 & $p=0.000 * * *$ & 0.612 & 30.7 & 5.2 & $p=0.004^{* *}$ & 0.363 \\
\hline \multicolumn{10}{|l|}{ Education $^{3}$} \\
\hline Illiterate, no sch. & 53 & 33.5 & 4.9 & $\chi^{2}=3.636$ & & 31.6 & 4.9 & $\chi^{2}=1.261$ & \\
\hline$<8$ years & 159 & 34.5 & 4.4 & $p=0.162$ & & 31.1 & 5.3 & $p=0.532$ & \\
\hline$>9$ years & 24 & 35.5 & 4.7 & & & 32.4 & 5.2 & & \\
\hline \multicolumn{10}{|l|}{ Marital status $^{3}$} \\
\hline Married & 148 & 35.1 & 4.4 & $\chi^{2}=12.973 \chi$ & & 32.3 & 4.9 & $\chi^{2}=15.053$ & \\
\hline Widowed & 80 & 33.2 & 4.4 & $\tilde{p}=0.002 * *$ & 0.422 & 29.7 & 5.3 & $\ddot{p}=0.001 * *$ & 0.526 \\
\hline Single & 8 & 32.6 & 6.1 & & & 28.8 & 6.8 & & \\
\hline \multicolumn{10}{|l|}{ Living situation $^{3}$} \\
\hline With spouse & 120 & 35.0 & 4.4 & $\chi^{2}=8.395 \chi$ & & 32.9 & 4.9 & $\chi^{2}=20.472$ & \\
\hline With relative & 39 & 33.0 & 4.8 & $\left.p=0.015^{*}\right\}$ & 0.447 & 28.5 & 5.3 & $p=0.000 * * *$ & 0.862 \\
\hline Alone & 34 & 34.0 & 4.2 & & & 30.7 & 5.6 & & \\
\hline \multicolumn{10}{|l|}{ Residence $^{2}$} \\
\hline Own home & 193 & 34.8 & 4.4 & $z=2.838$ & & 31.8 & 5.1 & $z=2.697$ & \\
\hline Relative's home & 42 & 32.6 & 4.8 & $p=0.005^{* *}$ & 0.475 & 29.2 & 5.4 & $p=0.007 * *$ & 0.489 \\
\hline \multicolumn{10}{|l|}{ MMSE levels ${ }^{3}$} \\
\hline Mild $>20$ & 76 & 34.1 & 4.5 & $\chi^{2}=1.777$ & & 30.1 & 5.3 & $\chi^{2}=0.821$ & \\
\hline Moderate $11-20$ & 154 & 34.7 & 5.6 & $p=0.411$ & & 30.6 & 5.5 & $p=0.663$ & \\
\hline \multirow[t]{2}{*}{ Severe $\quad<11$} & 6 & 33.0 & 6.8 & & & 30.1 & 2.9 & & \\
\hline & & rho & $p$ & & & rho & $p$ & & \\
\hline $\mathrm{DAD}^{4}$ & 236 & 0.179 & 0.00 & & & 0.565 & 0.00 & & \\
\hline NPI & 236 & & & & & & & & \\
\hline A Delusions & & -0.017 & 0.79 & & & -0.076 & 0.24 & & \\
\hline B Hallucinations & & -0.001 & 0.98 & & & -0.046 & 0.48 & & \\
\hline C Agitation & & 0.085 & 0.19 & & & -0.195 & 0.00 & & \\
\hline D Depression & & -0.289 & 0.00 & $* * *$ & & -0.318 & 0.00 & & \\
\hline E Anxiety & & -0.145 & 0.02 & & & -0.188 & 0.00 & & \\
\hline F Elation & & -0.058 & 0.37 & & & -0.170 & 0.00 & & \\
\hline G Apathy & & -0.204 & 0.00 & & & -0.504 & 0.00 & & \\
\hline H Disinhibition & & -0.026 & $0.68^{\prime}$ & & & -0.123 & 0.05 & & \\
\hline I Irritability & & 0.082 & 0.21 & & & -0.122 & 0.06 & & \\
\hline J Aber. motor beh. & & -0.065 & 0.32 & & & -0.133 & 0.04 & & \\
\hline $\mathrm{K}$ Sleep disorders & & -0.064 & 0.33 & & & -0.082 & 0.20 & & \\
\hline L Appetite & & -0.144 & $0.02^{\prime}$ & & & -0.250 & 0.00 & & \\
\hline Total & & -0.223 & 0.00 & & & -0.472 & 0.00 & & \\
\hline CAMGOC-R & 236 & -0.056 & 0.39 & & & 0.097 & 0.13 & & \\
\hline
\end{tabular}

${ }^{*} \mathrm{p}<0.05 ; * * \mathrm{p}<0.01 ; * * * \mathrm{p}<0.001 . \quad \quad{ }^{1}$ Pearson's coeff; ${ }^{2}$ Mann-Whitney U; ${ }^{3}$ Kruskal-Wallis; ${ }^{4}$ Spearman's coeff.

QoL-AD: Quality of Life in Alzheimer's Disease; MMSE: Mini Mental State Examination; DAD: Disability Assessment for Dementia; NPI: Neuropsychiatric Inventory; CAMCOG-R: Cambridge Cognitive Examination-Revised. 
Table 5. Caregiver factors and relationships with the QoL-AD scale for patients and caregivers

\begin{tabular}{|c|c|c|c|c|c|c|c|c|c|}
\hline \multirow[b]{2}{*}{ Caregiver factors } & \multirow[b]{2}{*}{$\mathbf{n}$} & \multicolumn{4}{|c|}{ QoL-AD patients } & \multicolumn{4}{|c|}{ QoL-AD caregivers } \\
\hline & & Mean & s.d. & p & Cohen's d & Mean & s.d. & $\mathbf{p}$ & Cohen's d \\
\hline Age $^{1}$ & 236 & 59.9 & 14.6 & \multicolumn{2}{|l|}{$\begin{array}{l}\mathrm{r}=0.230 \\
p=0.000^{* * *}\end{array}$} & 59.9 & 14.6 & \multicolumn{2}{|l|}{$\begin{array}{l}\mathrm{r}=0.174 \\
p=0.009^{* *}\end{array}$} \\
\hline \multicolumn{10}{|l|}{ Gender $^{2}$} \\
\hline Male & 70 & 33.7 & 4.8 & \multicolumn{2}{|l|}{$z=-1.246$} & 31.1 & 5.4 & \multicolumn{2}{|l|}{$z=-0.470$} \\
\hline Female & 166 & 34.7 & 4.4 & \multicolumn{2}{|l|}{$p=0.213$} & 31.4 & 5.2 & \multicolumn{2}{|l|}{$p=0.638$} \\
\hline \multicolumn{10}{|l|}{ Education $^{3}$} \\
\hline Illiterate, no sch. & 30 & 34.6 & 3.6 & \multicolumn{2}{|l|}{$\chi^{2}=0.094$} & 30.3 & 4.8 & \multicolumn{2}{|l|}{$\chi^{2}=4.162$} \\
\hline$<8$ years & 83 & 34.4 & 4.7 & & 32.1 & 4.9 & \multicolumn{2}{|l|}{$p=0.125$} \\
\hline$>9$ years & 120 & 34.8 & 4.7 & & & 31.0 & 5.5 & & \\
\hline \multicolumn{10}{|l|}{ Marital status ${ }^{3}$} \\
\hline Single & 15 & 33.3 & 5.3 & \multicolumn{2}{|l|}{$\chi^{2}=2.137$} & 29.4 & 4.1 & \multicolumn{2}{|l|}{$\chi^{2}=4.896$} \\
\hline Married & 204 & 34.6 & 4.4 & \multicolumn{2}{|l|}{$p=0.544$} & 31.6 & 5.3 & \multicolumn{2}{|l|}{$p=0.180$} \\
\hline Widowed & 8 & 32.0 & 6.2 & & & 29.9 & 6.0 & & \\
\hline Divorced & 9 & 34.7 & 4.9 & & & 29.5 & 5.1 & & \\
\hline \multicolumn{10}{|c|}{ Family relationship ${ }^{3}$} \\
\hline Spouse & 103 & 35.5 & 4.2 & \multicolumn{2}{|l|}{$\chi^{2}=11.870$} & 32.9 & 4.4 & \multicolumn{2}{|l|}{$\left.\chi^{2}=21.143\right\}$} \\
\hline Son/daughter & 109 & 33.5 & 4.6 & \multirow{2}{*}{$\tilde{p}=0.003 * *\}$} & \multirow[t]{2}{*}{0.463} & 30.5 & 5.4 & $\mathrm{p}=0.000 * *$ & 0.477 \\
\hline Other relative & 23 & 33.7 & 4.8 & & & 27.7 & 5.5 & & \\
\hline Living with patient & & & & & & & & & \\
\hline Yes & 153 & 34.8 & 4.5 & $z=2.060$ & & 31.9 & 5.1 & $z=2.424$ & \\
\hline No & 83 & 33.6 & 4.6 & $p=0.039^{*}$ & 0.275 & 30.3 & 5.3 & $\mathrm{p}=0.015^{*}$ & 0.308 \\
\hline Sole caregiver $^{2}$ & & & & & & & & & \\
\hline Yes & 137 & 35.1 & 4.4 & $z=2.977$ & & 32.3 & 4.9 & $z=3.416$ & \\
\hline No & 98 & 33.3 & 4.5 & $\mathrm{p}=0.003 * *$ & 0.398 & 29.9 & 5.4 & $\mathrm{p}=0.001 * *$ & 0.470 \\
\hline Other family burde & & & & & & & & & \\
\hline Yes & 87 & 33.4 & 4.9 & $z=-2.372$ & & 30.4 & 5.5 & $z=-2.206$ & \\
\hline No & 149 & 35.0 & 4.3 & $\mathrm{p}=0.018^{*}$ & -0.340 & 31.9 & 5.0 & $\mathrm{p}=0.027^{*}$ & -0.286 \\
\hline Employment situati & & & & & & & & & \\
\hline Retired & 98 & 35.2 & 4.5 & $\chi^{2}=6.919$ & & 32.2 & 4.8 & $\chi^{2}=4.804$ & \\
\hline In work & 101 & 33.7 & 4.5 & $\mathrm{p}=0.075$ & & 31.0 & 5.3 & $\mathrm{p}=0.187$ & \\
\hline Domestic work & 26 & 34.7 & 4.4 & & & 29.7 & 5.8 & & \\
\hline Unemployed & 8 & 33.0 & 5.6 & & & 30.1 & 6.4 & & \\
\hline SF-12 ${ }^{4}$ & 234 & rho & $p$ & & & rho & $p$ & & \\
\hline SF-12 Physical & & -0.092 & 0.162 & & & -0.059 & 0.371 & & \\
\hline SF-12 Mental & & 0.110 & 0.094 & & & 0.311 & $0.000 *$ & & \\
\hline CBI. Zarit & 236 & -0.149 & 0.022 & & & -0.562 & $0.000 *$ & & \\
\hline
\end{tabular}

${ }^{*} \mathrm{p}<0.05 ; * * \mathrm{p}<0.01 ; * * * \mathrm{p}<0.001 . \quad{ }^{1}$ Pearson's coeff; ${ }^{2}$ Mann-Whitney U; ${ }^{3}$ Kruskal-Wallis; ${ }^{4}$ Spearman's coeff.

QoL-AD: Quality of Life in Alzheimer's Disease; SF-12: Short Form of Health Survey; CBI: Caregiver Burden Interview. 


\begin{tabular}{|c|c|c|c|c|}
\hline \multicolumn{5}{|c|}{ Table 6. Multivariate linear regression analysis } \\
\hline \multirow[t]{2}{*}{ Patient factors $^{\mathrm{a}}$} & \multicolumn{2}{|c|}{ QoL-AD patients } & \multicolumn{2}{|c|}{ QoL-AD caregivers } \\
\hline & Beta & $p$ & Beta & $p$ \\
\hline Gender & -0.232 & $0.001 * *$ & -0.098 & 0.077 \\
\hline 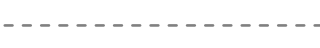 & & ----- & 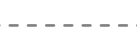 & \\
\hline DAD & 0.164 & $0.023 *$ & 0.393 & $0.000 * * *$ \\
\hline NPI D Depression & -0.278 & $0.000 * * *$ & -0.170 & $0.003 * *$ \\
\hline NPI G Apathy & -0.049 & 0.502 & -0.227 & $0.000 * * *$ \\
\hline \multirow[t]{2}{*}{ Caregiver factors $^{b}$} & \multicolumn{2}{|c|}{ QoL-AD patients } & \multicolumn{2}{|c|}{ QoL-AD caregivers } \\
\hline & Beta & $p$ & Beta & $p$ \\
\hline Age & 0.198 & $0.039 *$ & -0.149 & 0.074 \\
\hline Relationship & 0.019 & 0.841 & -0.204 & $0.013^{*}$ \\
\hline SF-12 Mental & & .......... & 0.143 & $0.024 *$ \\
\hline CBI Zarit & -0.135 & $0.049 *$ & -0.452 & $0.000 * * *$ \\
\hline
\end{tabular}

$$
\begin{aligned}
& { }^{\mathrm{a}} \mathrm{r}^{2}=0,298 ;{ }^{\mathrm{b}} \mathrm{r}^{2}=0,522 \\
& { }^{*} \mathrm{p}<0.05 ; * * \mathrm{p}<0.01 ; * * * \mathrm{p}<0.001
\end{aligned}
$$

Adjusted for:

- Non-significant patient factors: Age, Marital status, Living situation, Residence, NPI-Agitation, NPI-Anxiety, NPI-Elation, NPI-Aber. motor beh., NPI-Appetite.

- Non-significant caregiver factors: Living with patient, Sole carer, Other family burden

QoL-AD: Quality of Life in Alzheimer's Disease; DAD: Disability Assessment for Dementia; NPI: Neuropsychiatric Inventory; SF-12: Short Form of Health Survey; CBI: Caregiver Burden Interview 